\title{
Rancang Bangun Alat Pengeringan Cengkeh Dengan Sistem Peringatan Suara
}

\author{
Yultrisna $^{1}$, Tuti Angraini ${ }^{2}$, Ozi firmansyah $\mathrm{Gani}^{3}$ \\ ${ }^{123}$ Jurusan Teknik Elektro Politeknik Negeri Padang \\ yultrisna@pnp.ac.id \\ Kampus Politeknik Negeri Padang, Limau Manis Padang
}

\begin{abstract}
The amount of clove demand in Indonesia continues to increase, often dry-ready cloves are scarce when the rainy season arrives. Farmers have difficulty in draining their crop cloves. So that producers, especially producers of clove cigarettes, are always looking for ways to keep producing their products every day. Designing a Clove Dryer with a Sound Warning System aims to help clove farmers in the drying process. The advantage of using this tool is that it can help speed up the clove drying process compared to traditional drying and can be a solution when the rainy season arrives. The design of this tool consists of hardware and software, this tool uses the Uno microcontroller, uses DHT22 as a temperature sensor programmed as input so that the tool can read the drying temperature, the heating element will turn on and off when the temperature is over and the fan also functions as a waster excessive heat. For monitoring using 16x2 LCD as a display of temperature, humidity and drying time. The loudspeaker functions as the drying marker is over and gives a sound warning. The Mosfet driver uses the fan control, the clove drying time is around 19 hours.
\end{abstract}

Keywords: Clove Dryer, Sound Warning, DHT22, Microcontroller, Fan, Heating Element, LCD 16x2, LoudSpeaker

\begin{abstract}
Abstrak - Besarnya permintaan cengkeh di Indonesia terus meningkat, seringkali cengkeh kering siap jual menjadi langka saat musim penghujan tiba. Petani mengalami kesulitan dalam pengeringan cengkeh basah hasil panenan mereka. Sehingga para produsen terutama produsen rokok kretek selalu mencari cara agar tetap menghasilkan produknya setiap hari Rancang Bangun Alat Pengering Cengkeh dengan Sistem Peringatan Suara ini bertujuan untuk membantu para petani cengkeh dalam proses pengeringan. Keuntungan dengan menggunakan alat ini adalah dapat membantu mempercepat proses pengeringan cengkeh dibandingkan dengan pengeringan secara tradisional serta dapat menjadi solusi saat musim penghujan tiba. Perancangan alat ini terdiri dari perangkat keras dan perangkat lunak, alat ini menggunakan mikrokontroler Uno, menggunakan DHT22 sebagai sensor suhu yang di program sebagai input agar alat dapat membaca suhu pengeringan, elemen pemanas akan aktif dan mati ketika suhu berlebih serta fan yang juga befungsi sebagai pembuang panas yang berlebih. Untuk monitoring menggunakan LCD 16x2 sebagai tampilan suhu, kelembaban dan lama waktu pengeringan. Loudspeaker berfungsi sebagai penanda pengeringan telah usai dan memberikan peringatan berupa suara. Pada pengontrolan fan digunakan driver Mosfet, lama waktu pengeringan cengkeh adalah sekitar 19 jam.
\end{abstract}

Kata kunci: Alat Pengering Cengkeh, Peringatan Suara, DHT22, Mikrokontroler, Fan, Elemen Pemanas, LCD 16x2, LoudSpeaker

(C) 2017 Elektron Jurnal Ilmiah

\section{I.PENDAHULUAN}

Perkembangan dunia pertanian dewasa ini sangat pesat guna memenuhi tuntutan kebutuhan umat manusia. Pertanian merupakan bagian dari ilmu pengetahuan dan teknologi serta inovasi yang tengah berjalan seiring dengan kemajuan zaman. Penyebab dari keadaan ini adalah kebutuhan manusia akan kemudahan dan efisiensi penggunaan energi dalam berbagai bidang pertanian, namun bentuk tetap ringkas serta berpenampilan menarik.

Cengkeh (Syzygium aromaticum) adalah tanaman perkebunan yang dapat mencapai ketinggian hingga 20 meter. Daun mudanya berwarna merah muda terang, lalu berubah menjadi hijau kekuningan setelah tua dan menjadi keras. Bagian yang diambil dari tanaman cengkeh adalah bunga dan daunnya. Bunga cengkeh berkelompok mulai tiga hingga sepuluh tangkai, di mana setiap tangkai berisi rata-rata tiga kuntum bunga. Cengkeh merupakan produk rempah yang dipergunakan sebagai salah satu bahan baku industri rokok kretek, farmasi, kosmetik, dan rempahrempah. Wahyudi [1] menyebutkan bahwa Industri rokok kretek merupakan pengguna terbesar (80-90\%) dari komoditas cengkeh, sedang sisanya dipergunakan untuk penggunaan lain. Besarnya permintaan cengkeh dengan demikian akan sangat ditentukan oleh perkembangan jumlah produksi rokok kretek terutama di wilayah Indonesia. Hingga saat ini perkembangan industri rokok kretek di Indonesia terus meningkat, maka dari itu permintaan akan cengkeh akan selalu mengikutinya. Cengkeh kering siap jual seringkali menjadi langka ketika musim hujan berlangsung. Supply cengkeh kering dari petani sedikit dan lamban pada musim penghujan. Petani mengalami kesulitan dalam pengeringan cengkeh basah hasil panenan mereka.

Cengkeh dapat dikeringkan pada musim kemarau dengan bantuan sinar matahari selama 4 hingga 5 hari 
dengan rata-rata waktu jemur antara 8 hingga 10 jam untuk setiap harinya. Lama proses pengeringan cengkeh bertambah menjadi 6 hingga 10 hari bahkan lebih pada musim penghujan tergantung pada intensitas hujan pada waktu proses pengeringan cengkeh. Cengkeh setelah kering memiliki kadar air berkisar antara 8 hingga $10 \%$ dan berwarna merah kecoklatan. Untuk setiap 3 kilogram cengkeh basah rata-rata akan menjadi 1 kilogram cengkeh setelah kering. Bertambahnya waktu proses pengeringan cengkeh saat musim penghujan mengakibatkan terjadinya antrian lahan untuk proses pengeringan cengkeh. Petani harus menunggu lahan kering terlebih dahulu dari kelembaban paska terjadi hujan untuk melakukan proses pengeringan cengkeh mereka. Pengeringan cengkeh dengan mengandalkan bantuan sinar matahari hanya dapat dilakukan pada siang hari saja, sedangkan pada malam hari proses pengeringan cengkeh tidak dapat dilakukan. Pengeringan cengkeh dengan bantuan sinar matahari ketika musim kemarau dapat berlangsung dengan baik bagi petani yang memiliki lahan relatif luas. Hambatan pada musim kemarau yang muncul adalah ketika petani tidak memiliki lahan pengeringan yang luas untuk mengeringkan cengkeh hasil panenannya. Antrian cengkeh basah yang belum dikeringkan karena faktor lahan dan hujan mengakibatkan cengkeh basah menumpuk di tangan petani. Hal tersebut mengakibatkan cengkeh basah dijual dengan harga murah karena dihawatirkan tidak mendapat giliran waktu dalam proses pengeringan hingga pada akhirnya cengkeh tersebut terfermetasi dan membusuk. Banyaknya jumlah cengkeh basah yang dijual oleh petani mengakibatkan harga dari cengkeh basah menjadi anjlok.

Dalam beberapa hasil pengujian dan beberapa data literatur tentang pengeringan cengkeh dihasilkan bahwa kondisi optimum untuk pengeringan cengkeh adalah pada suhu $40^{\circ} \mathrm{C}$ sampai $60^{\circ} \mathrm{C}$. Jika dibandingkan dengan hasil pengeringan secara tradisional menggunakan matahari dengan pengeringan buatan menunjukan mutu yang berbeda. Secara umum kondisi penampakan hasil keduanya sama, yaitu mempunyai warna coklat-hitam, ukuran seragam tidak ada cengkeh yang rusak, tidak ada gagang cengkeh dan kadar air dibawah $14 \%$. Namun kadar minyak atsiri pada cengkeh dengan pengeringan buatan lebih tinggi dari pengeringan secara tradisional, karena metode ini cengkeh akan terkena radiasi langsung dari matahari yang menyebabkan suhu cengkeh bisa cukup tinggi yang mengakibatkan penguapan minyak atsiri.

Dengan alat ini kita dapat melakukan penuruan kadar air dan perubahan suhu yang terjadi didalam box pengering dapat dipantau dengan pencapaian suhu setpoint yang diinginkan berdasarkan pembacaan dari sensor.
Untuk mengatasi hal tesebut pernah dibuat alat dengan judul "Rancang Bangun Sistem Pengeringan Cengkeh Menggunakan Fuzzy Logic" oleh Reno Fajar Sidiq pada tahun 2016[2], alat itu memanfaatkan sensor LM35 sebagai sensor suhu dan menggunakan metoda Fuzzy Logic untuk sistem pengeringan. Namun pada alat tersebut masih mengalami kekurangan diantaranya tingkat kematangan yaang kurang merata, dimana pada bagian atas dimana heater diletakkan, cengkeh tampak lebih matang duluan daripada bagian bawahnya. Dan juga penggunaan sensor LM35 hanya dapat menampilkan output berupa suhu saja sedangkan untuk kelembapan tidak. Padahal untuk pengeringan cengkeh perlu diketahui kadar air yang ada pada cengkeh serta kadar air udara sekitar sebagai perbandingan dan menjaga kualitas cengkeh. Berdasarkan masalah yang masih timbul dengan hal diatas, maka dari itu penulis membuat sebuah alat berjudul "Rancang Bangun Alat Pengering Cengkeh dengan Sistem Peringatan Suara". Penelitian ini bertujuan agar pengeringan cengkeh dapat dilakukan walau dalam keadaan bukan musin kemarau dan juga dengan pengeringan yang tidak hanya mengukur suhu tetapi juga melibatkan kadar air yang ada didalam box pengering yang mana pada sistem pengeringan cengkeh dengan kadar air harus dibawah $14 \%$.

\section{METODE PENELITIAN}

Adapun dalam perancangan sistem adalah membuat suatu blok diagram sebagai acuan, dimana setiap blok mempunyai fungsi tertentu dan saling terkait sehingga membentuk sistem dari alat yang di buat kemudian dilakukan perancangan perangkat keras (hardware) dan perancangan perangkat lunak (software).

\section{A. Blok Diagram Sistem}

Prinsip kerja alat ini dikelompokkan menjadi 3 bagian utama yakni, proses input, pengolahan data serta proses output. Pada proses input, input yang diinginkan diatur melalui setpoint pada mikrokontroler arduino agar dapat mengaktifkan plant (heater). Pada saat daya alat ini diberi daya input $220 \mathrm{~V} \mathrm{AC}$, heater akan aktif dan sensor DHT22 akan membaca suhu ruangan pada box pengering dan ditampilkan lewat LCD. Pada proses/tahap pengeringan, heater akan tetap bekerja pada batas suhu normal dari setpoint (dibawah suhu $47^{\circ} \mathrm{C}$ ). Apabila suhu berada diantara $47^{\circ} \mathrm{C}$ sampai dengan dibawah $49^{\circ} \mathrm{C}$ maka heater yang aktif hanya pada bagian bawah saja. Apabila suhu sama dengan $49^{\circ} \mathrm{C}$ sampai dengan dibawah $50^{\circ} \mathrm{C}$ maka heater atas dan bawah akan mati, seperti yang terlihat pada gambar 1 . 


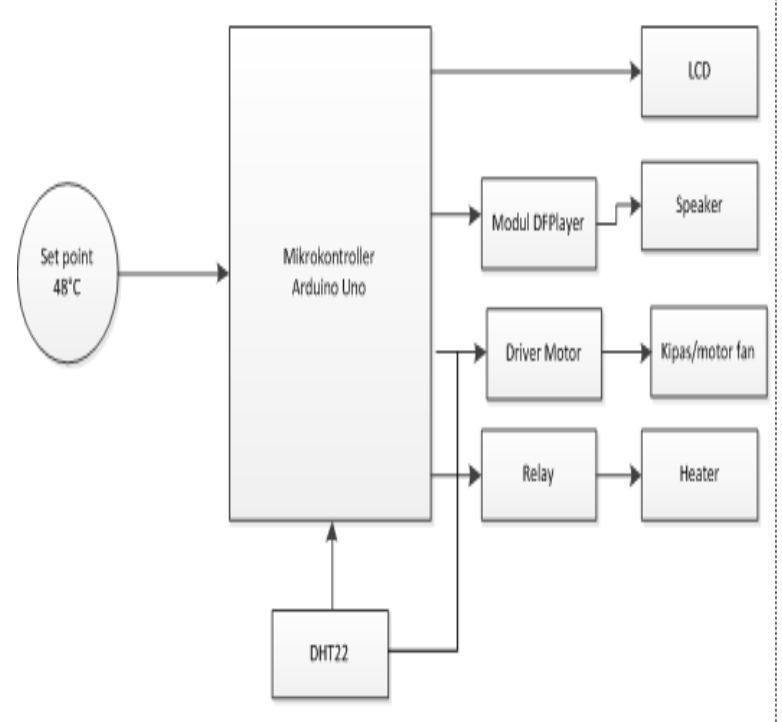

Gambar 1. Blok Diagram sistem

Dan apabila suhu berada pada $50^{\circ} \mathrm{C}$ hingga lebih maka heater atas dan bawah mati dengan fan yang berputar dengan PWM 160. Pada bagian output terdapat heater, LCD, fan, dan speaker. Heater berfungsi sebagai elemen pemanas dalam box pengering, terdapat 2 tipe elemen pemanas pada alat ini yakni dengan daya 2 buah dengan daya 10 Watt serta 1 buah dengan daya 25Watt. Elemen pemanas akan bekerja sesuai dengan perintah program yang diinginkan dengan tujuan suhu tertentu. Elemen pemanas dapat dimatikan dan dihidupkan kembali dengan mengatur kerja relay. Data tampilan LCD dapat melihat data kenaikan dan penurunan suhu lewat sensor DHT22 dan kondisi kecepatan hitungan waktu. Lalu fan akan bekerja dengan bantuan driver guna memberikan nilai PWM yang diinginkan agar dapat membuang udara panas berbelebih pada bagian box pemamas. Sedangkan loudspeaker yang berguna untuk menampilkan informasi berupa suara hasil rekaman dan alarm lewat modul DFlayer yang memberikan informasi berkaitan hasil setelah pengeringan selesai.

\section{B. Perancangan Hardware}

Arduino Uno memiliki 54 pin I/O digital dimana 15 pin diantaranya dapat digunakan sebagai output Pulse Width Modulation (PWM), 16 input analog. Pemasangan komponen pada mikrokontroler dengan menggunakan bantuan pin header dan kabel konektor yang bertujuan memudahkan pengguna untuk memasang, memindahkan ke pin yang dibutuhkan. Berikut skematik rangkaian keseluruhan mikrokontroler pada gambar dibawah ini

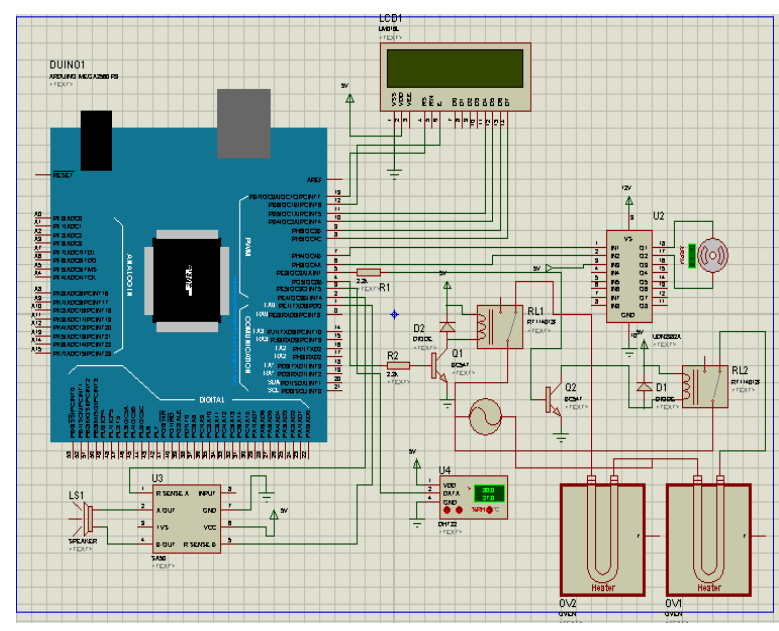

Gambar 2. Skematik Rangkaian Keseluruhan pada Mikrokontroler

Rangkaian power supply berfungsi sebagai sumber tegangan utama, dimana pada rangkaian ini memanfaatkan tegangan dari jala-jala PLN sebesar $220 \mathrm{~V}$ AC. Lalu lewat tegangan tersebut digunakan sebuah trafo step down 3A dengan keluaran tegangannya yakni $12 \mathrm{~V}$ AC. Selanjutnya dengan rangkaian penyearah gelombang penuh lewat dioda sehingga tegangan AC dikonversikan menjadi tegangan DC. Rangkaian driver ini berfungsi untuk menggerakkan dan mengontrol motor DC pada fan. Pengontrolan kecepatan putaran dari fan ini mempengaruhi suhu dan kelembaban di dalan box pengering. Pada rangkaian ini menggunakan sebuah fan/motor kipas yang dipasang pada bagian belakang tengah dari bagian box pengering. Pengontrolan kecepatan motor fan dilakukan dengan prinsip kerja PWM pada arduino. Rangkaian ini memiliki 2 buah data input untuk 1 motor saja. Pada driver ini memiliki beberapa transistor dan mosfet yang dihubungkan secara paralel. Driver ini bekerja dengan mempertimbangkan nilai input yang masuk pada rangkaian.

Relay berfungsi berfungsi untuk melewatkan arus AC yang dibutuhkan untuk dapat menghidupkan heater. Dikarenakan input tegangan untuk pengaktifan heater adalah $220 \mathrm{~V}$ AC maka dibutuhkan rangkaian relay yang dapat menghidup dan matikan elemen pemanas. Relay yang digunakan adalah modul relay dengan koil 5 V DC. Prinsip kerja dari sebuah relay adalah relay akan aktif jika mendapat picu tegangan dari mikrokontroler lewat pin input modul relay. Pada input relay ini terdapat aktif low atau aktif high yang akan dihubungkan ke mikrokontroler arduino, jadi pengguna dapat menentukan kedaan aktif saat input diberikan high atau low. Dan juga pada output relay terdapat NO (Normally Open) dan NC (Normally Close) dimana output (heater) akan aktif dalam keadaan terbuka atau tertutup. Sensor DHT22 merupakan sensor yang dapat membaca nilai kelembaban dan nilai suhu ruangan. Didalam sensor 
ini terdapat termistor tipe NTC (Negatif Temperature Coeffisient) untuk mengatur suhu dan kelembaban tipe resistif. Didalam alat ini penulis menggunakan modul dari sensor DHT22 yang telah didapasangi resistor senilai $5 \mathrm{k} \Omega$ untuk membagi tegangan agar terbaca oleh mikrokontroler. Pada sensor ini merupakan sensor dengan data digital input. Modul DFPlayer berfungsi sebagai media penyimpanan suara berupa mp3 dan juga penghubung antara speaker dengan mikrokontroler arduino.

\section{Perancangan Perangkat Lunak (Software)}

Setelah melakukan perancangan perangkat keras maka selanjutnya adalah melakukan perancangan perangkat lunak. Perancangan perangkat lunak seiring dengan perancangan perangkat keras. Hal ini dilakukan karena perangkat lunak yang berfungsi untuk mengendalikan peralatan tersebut. Bahasa pemograman yang digunakan pada tugas akhir ini adalah bahasa $\mathrm{C}$.

Perancangan perangkat lunak adalah perancangan yang meliputi tentang algoritma dari alat dan pemilihan software yang digunakan untuk pemograman alat. Software yang digunakan untuk pemograman alat ini adalah software arduino. Arduino adalah salah satu software yang menggunakan bahasa pemograman $\mathrm{C}++$. Perancangan algoritma diperlukan guna memudahkan dalam membuat flowchart dan pembuatan program. Dengan adanya suatu algoritma yang baik maka akan menjadi suatu faktor keberhasilan dalam perancangan software. Dalam alat ini algoritma yang dirancang adalah sebagai berikut :

1. Membuat program dengan menginisialisasi penggunaan variabel maupun konstanta dalam program

2. Setelah program selesai di upload maka memulai dengan memulai dengan menghidupkan saklar yang terhubung pada power supply

3. Saat tegangan telah masuk ke arduino maka heater akan secara otomatis hidup dengan suhu yang ditampilkan oleh LCD dengan tampilan "WELCOME". Kemudian terjadilah proses pengeringan yang diinginkan

4. Pada proses pengeringan :

a). Jika suhu berada dibawah $47^{\circ} \mathrm{C}$ maka pada elemen pemenas atas dan bawah akan tetap aktif

b). Jika suhu berada diantara $47^{\circ} \mathrm{C}$ sampai dibawah $49^{\circ} \mathrm{C}$ maka elemen pemanas atas akan mati dan elemen pemanas bawah akan tetap aktif

c). Jika suhu berada pada $49^{\circ} \mathrm{C}$ sampai dengan dibawah $50^{\circ} \mathrm{C}$ maka elemen pemanas atas dan bawah akan mati

d). Jika suhu berada pada $50^{\circ} \mathrm{C}$ hingg lebih maka elemen pemanas atas dan bawah akan mati dan fan aktif dengan PWM 160

5. Proses pengeringan akan berhenti jika batas hitungan waktu pada arduino telah selesai dan tampilan LCD "HEATING IS OVER PLEASE TURN OFF" juga dengan speaker yang berbunyi dengan memberikan peringatan/isyarat.

6. Kemudian program akan berakhir.

Flowchart atau diagram alir adalah urutan instruksi-instruksi pada pembuatan suatu program. Pembuatan flowchart diperlukan untuk mempermudah dalam pembuatan program dapat dilihat pada gambar berikut :

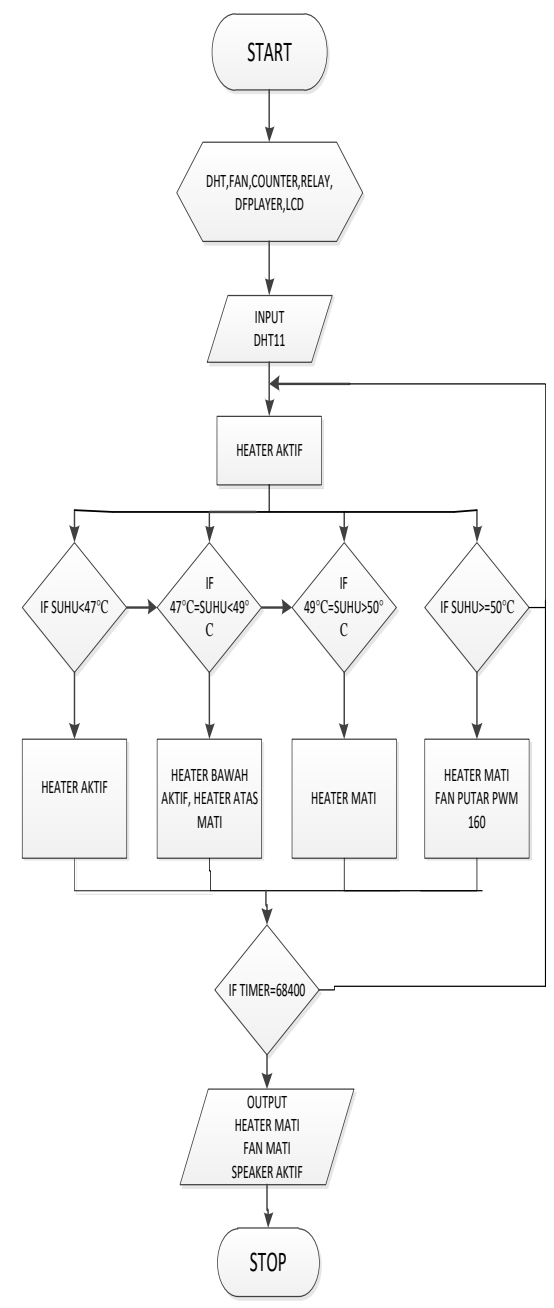

Gambar 3. Flowchart Pengeringan Cengkeh

\section{Perancangan Mekanik}

Dalam perancangan mekanik terdapat dua bagian dalam perancangan yaitu box rangkaian dan box pengering. Untuk dimensi alat keseluruhan adalah $47 \mathrm{~cm} \times 31 \mathrm{~cm} \times 31 \mathrm{~cm}$. Adapun fungsi dari masingmasing bagian diantaranya :

1. Box rangkaian digunakan sebagai tempat rangkaian seperti, rangkaian catu daya, trafo, arduino, LCD, DFPlayer serta speaker. 
Berikut pada gambar 4 design body secara keseluruhan.

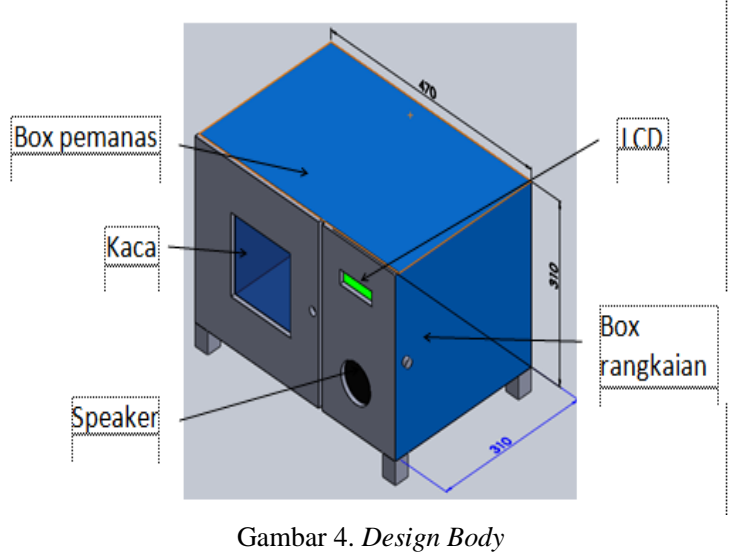

2. Box pemanas digunakan sebagai tempat memanaskan cengkeh basah dengan menggunakan heater yang terdapat pada bagian atas sebanyak 1 buah dengan daya 25 Watt dan bawah sebanyak 2 buah dengan daya masing-masing 10 watt dari box pemanas tersebut. Serta juga terdapat kipas yang berfungsi untuk mengeluarkan udara panas dari dalam box.

\section{HASIL DAN PEMBAHASAN}

Pengujian alat di lakukan guna untuk mengetahui apakah pembuatan alat yang telah di lakukan sesuai dengan keinginan serta fungsi dari alat itu sendiri. Pengujian alat terdiri dari beberapa pengujian terhadap alat dan rangkaian yang telah dibuat. Hal itu dapat dilihat dari hasil-hasil yang diperoleh dalam pengujian sistem. Selain itu pengujian juga dilakukan untuk mengetahui kelebihan dan kekurangan dari sistem yang dibuat. Setelah mendapatkan hasil dari pengujian kemudian hasil tersebut dianalisa agar dapat dipahami atas alat yang telah dibuat. Untuk itu berikut langkahlangkah dan pokok pembahasan yang akan dilakukan pengujian sebagai berikut :

\section{Sensor DHT22 \\ 2. Relay \\ 3. Rangkaian Driver Mosfet \\ 4. Elemen Pemanas}

\section{A. Pengujian dan Analisa Sensor DHT22}

Rangkaian sensor DHT22 merupakan rangkaian yang digunakan untuk mengukur suhu pada area box pengering, dimana dengan input 5 VDC dan data digital yang bersumber dari arduino. Pengujian sensor ini dilakukan dengan cara memanaskan elemen pemanas lalu dibantu dengan termometer untuk perbandingan suhu dengan sensor nantinya dan juga suhu akan diketahui lewat tampilan LCD dan secara keseluruhan di program lewat mikrokontroler arduino

uno. Berdasarkan pengujian dan pengukuran maka didapatkan hasil pada tabel 1 dibawah ini :

\begin{tabular}{cccc} 
Tabel 1. Pengukuran Suhu dengan Sensor Suhu DHT22 \\
\hline No & Suhu & Sensor & Error \\
& Termometer $\left({ }^{\circ} \mathrm{C}\right)$ & DHT22 &
\end{tabular}

$\left({ }^{\circ} \mathrm{C}\right)$

\begin{tabular}{cccc}
\hline 1 & 35 & 35,20 & 0,2 \\
\hline 2 & 40 & 40,90 & 0,9 \\
\hline 3 & 45 & 46 & 1 \\
\hline 4 & 50 & 50,40 & 0,4 \\
\hline 5 & 55 & 55,10 & 0,1 \\
\hline 6 & 60 & 61 & 1 \\
\hline 7 & 65 & 65,50 & 0,5 \\
\hline 8 & 70 & 70,30 & 0,3 \\
\hline 9 & 75 & 75,20 & 0,2 \\
\hline
\end{tabular}

Berdasarkan pengujian dan pengukuran yang dilakukan pada sensor DHT22 maka dapat dikatakan sensor mempunyai nilai yang cukup peka terhadap suhu dan perubahannya, dimana bisa dilihat pada tabel 4 menunjukan nilai error yang dibawah nilai ambang batas yang berarti sensor DHT22 adalah sensor yang presisi. Hal ini diakibatkan oleh tipe sensor yang memiliki tingkat stabilitas yang sangat baik serta fitur kalibrasi yang sangat akurat. Koefisien kalibrasi disimpan dalam OTP program memory, sehingga ketika internal sensor mendeteksi sesuatu, maka module ini menyertakan koefisien tersebut dalam kalkulasinya. DHT22 termasuk sensor yang memiliki kualitas yang baik, dinilai dari respon, pembacaan data yang cepat, dan kemampuan anti-interference.

Untuk pembacaan suhu dan kelembaban pada modul sensor suhu DHT22 menggunakan sistem komunikasi satu jalur dalam atau biasa disebut single wire two way. Maksud dari single wire two way adalah dengan menggunakan satu kabel data arduino dapat membaca 2 data sekaligus yaitu data suhu dan kelembaban. Modul sensor suhu DHT22 akan mengirimkan HIGH dan LOW pada pin data untuk mengirim data pada modul arduino agar dapat menampilkan suhu dan kelembaban. Pada tahap pengaktifan awal modul arduino uno memberikan tegangan HIGH untuk pengaktifan modul sensor suhu DHT22. Selanjutnya modul sensor suhu DHT22 mengirimkan balasan ke modul arduino bahwa data telah diterima oleh modul sensor suhu DHT22. Pada tahap selanjutnya modul sensor suhu DHT22 akan mengirimkan data suhu dan kelembaban pada modul arduino sesuai waktu pergantian pulsa HIGH dan LOW . Data suhu dan kelembaban masing masing adalah 16 bit. Jadi untuk proses pembacaan data modul sensor suhu DHT22 akan mengirimkan LOW kemudian akan ditarik ke HIGH. Kemudian akan ditarik ke LOW untuk menandakan pergantian kondisi antara pin.. Begitu seterusnya proses pengiriman data suhu dan kelembaban pada modul sensor suhu DHT22. 


\section{B. Pengujian dan Analisa Relay}

Relay digunakan sebagai penghubung dan pemutus arus, dimana tegangan digunakan untuk beban 220 VAC dengan input relay agar aktif yakni 5 VDC. Pada relay terdapat kontak NO dan NC. Pada kontak tersebut akan apabila diberi logika LOW maka relay dari NO menjadi NC begitu sebaliknya. Hal itu dikarenakan relay yang digunakan adalah aktif LOW. Pengujian relay dapat dilakukan dengan mengukur tegangan input yang masuk pada relay dan kontak output pada relay (NO/NC) dengan bantuan multimeter yang akan memberikan respon terhadap aktif atau tidaknya relay pada bagian output (beban). Hasil pengujian dapat dilihat pada tabel 2 dibawah ini

Tabel 2. Hasil Pengujian Relay

\begin{tabular}{ccc}
\hline Logika & Tegangan & Keadaan Relay \\
\hline LOW & 5 VDC & Aktif \\
& & \\
\hline HIGH & 0 VDC & Mati
\end{tabular}

Adapun relay yang digunakan adalah modul relay dengan keadaan aktif LOW. Dimana berdasarkan hasil pengujian apabila mikrokontroler arduino memberikan logika LOW maka relay akan aktif dan memberikan tegangan 5 VDC sesuai dengan pin digital arduino yang digunakan dan sebaliknya apabila mikrokontroler arduino memberikan logika HIGH maka relay akan mati dengan tegangan keluaran pada arduino yakni 0 VDC. Jadi penggunaan modul relay ini dengan mikrokontroler melalui pin digital. Relay beroperasi pada tegangan kerja $5 \mathrm{~V}$ DC pada lilitan kawat seleoidnya. Cara kerja/prinsip kerja relay ketika solenoid atau lilitan kawat pada inti besi dialiri arus listrik, tuas akan tertarik karena adanya gaya magnet yang terjadi pada selenoid sehingga saklar akan menutup. Pada saat arus listrik ke selenoid atau lilitan koil dihentikan, gaya magnet akan hilamg, tuas akan kembali ke posisi semula dan kontak saklar kembali terbuka.

\section{Pengujian Rangkaian Driver Mosfet}

Tujuan melakukan pengujian rangkaian driver mosfet adalah untuk mengetahui berapa tegangan yang akan mengaktifkan motor fan berdasarkan kecepatan motor yang diberikan. Dengan input tegangan input 12 VDC yang menjadi sumber bagi driver mosfet dan tentunya akan masuk ke fan. Pengujian dilakukan dengan mengukur input dan output dari driver tersebut dengan bantuan multimeter dan osciloscope serta juga program pwm yang di upload ke dalam mikrokontroler arduino uno. Skematik pengujian rangkaian driver mosfet dapat dilihat pada gambar 5 . Hasil peng $. \cdot, \ldots ., \cdots+$

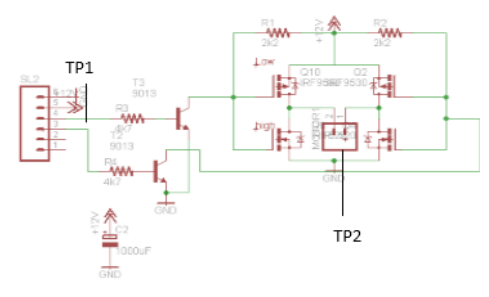

Gambar 5. Skematik Rangkaian Driver Mosfet

Tabel 8. Data Pengukuran PWM Driver Mosfet

\begin{tabular}{ccccccc}
\hline No & $\begin{array}{c}\text { Input } \\
\text { PWM }\end{array}$ & $\begin{array}{c}\text { Toff } \\
(\mathrm{ms})\end{array}$ & $\begin{array}{c}\text { Ton } \\
(\mathrm{ms})\end{array}$ & $\begin{array}{c}\text { Duty } \\
\text { Cycle } \\
(\%)\end{array}$ & $\begin{array}{c}\text { Tegangan } \\
\text { TP1(V) }\end{array}$ & $\begin{array}{c}\text { Tegangan } \\
\text { TP2(V) }\end{array}$ \\
\hline 1 & 10 & 0,923 & 0,100 & 39,22 & $0,2 \mathrm{~V}$ & $0,5 \mathrm{~V}$ \\
\hline 2 & 50 & 0,821 & 0,200 & 19,58 & $0,9 \mathrm{~V}$ & $2,4 \mathrm{~V}$ \\
\hline 3 & 100 & 0,622 & 0,400 & 39,13 & $1,9 \mathrm{~V}$ & $4,8 \mathrm{~V}$ \\
\hline 4 & 150 & 0,423 & 0,600 & 58,6 & $2,8 \mathrm{~V}$ & $7,1 \mathrm{~V}$ \\
\hline 5 & 200 & 0,224 & 0,800 & 78,12 & $3,8 \mathrm{~V}$ & $9,4 \mathrm{~V}$ \\
\hline 6 & 255 & 0 & 1,023 & 100 & $5 \mathrm{~V}$ & $12 \mathrm{~V}$ \\
\hline
\end{tabular}

Pada pengujian ini, fan dihubungkan ke pin arduino melalui driver mosfet .Ketika arus mengalir menuju basis transistor atau di beri logika "1" maka transistor dalam kondisi saturasi, arus mengalir dari kolektor menuju ke emitor dan rangkaian driver motor akan berfungsi mengeluarkan tegangan sebesar 12 Vdc tegangan ini yang nantinya akan menggerakan motor. Ketika di berikan logika "0" maka tidak ada arus yang mengalir ke basis transistor dan output driver motor pun bernilai $0 \mathrm{Vdc}$.

Transistor dalam keadaan kondisi cut off atau mati sehingga tidak ada arus yang mengalir dari kolektor ke emitor. Nilai logika 1 yang di berikan pada pin output driver motor berguna untuk mengatur putaran motor dimana nilai kecepatan motor berdasarkan dari pengolahan data PWM pada program mikrokontroller arduino sehingga tingkat kecepatan putaran motor dapat digunakan sebagai pengontrol suhu apabila suhu berlebih. Pada data pengujian hasil kecepatan motor fan yang dilihat lebar pulsanya yaitu yang bernilai 10 , $50,100,150,200$ dan 255, pada kecepatan motor 150 dan 200 dapat dilihat lebar pulsa HIGH nya lebih besar dari pada pulsa LOW ini yang menyebabkan nilai kecepatan putaran motor nya besar atau lebih cepat, begitu juga dengan nilai kecepatan motor 255 dimana nilai pulsanya semua bernilai HIGH sehingga putaran motornya akan sangat cepat karena tegangan yang diterima pada motor akan penuh tanpa terhenti.

\section{Pengujian Elemen Pemanas}

Elemen pemanas digunakan untuk mengeringkan cengkeh yang diletakan didalam box pengering bagian atas dan bawah. Pada bagian atas box pengeringan terpasang elemen pemanas dengan spesifikasi tegangan $220 \mathrm{~V}$ AC dengan daya 25 Watt. 
Pada bagian bawah box pengering dipasang 2 buah elemen pemanas dengan spesifikasi tegangan $200 \mathrm{~V}$ AC dengan daya 10Watt. Pengujian dilakukan dengan memberikan input pada elemen pemanas yang terhubung pada relay sebesar $220 \mathrm{~V}$ AC, dengan bantuan sensor suhu DHT22 sebagai pembaca nilai suhu yang terhubung dengan mikrokontroler. Hasil pengujian dapat dilihat pada tabel 4 .

Tabel 4. Data Pengukuran Kenaikan Suhu Elemen Pemanas

\begin{tabular}{ccc}
\hline No & Waktu(detik) & $\begin{array}{c}\text { Sensor } \\
\text { DHT22 }\end{array}$ \\
\hline 1 & 60 & 33,50 \\
\hline 2 & 120 & 36,60 \\
\hline 3 & 180 & 38,70 \\
\hline 4 & 240 & 41,40 \\
\hline 5 & 300 & 43,90 \\
\hline 6 & 360 & 45,80 \\
\hline 7 & 420 & 48,50 \\
\hline \multicolumn{2}{r}{ Rata-rata kenaikan suhu } & $2,5^{\circ} \mathrm{C}$ \\
\hline
\end{tabular}

Dari hasil pengujian dan pengukuran suhu elemen pemanas maka dapat dianalisa kenaikan suhu yang terjadi hingga mencapai setpoint sesuai dengan nilai pada tabel 4. Kenaikan suhu yang merupakan hasil dari ketiga elemen pemanas yang terletak di bagian box pengering. Kenaikan suhu hingga mencapai setpoint $48^{\circ} \mathrm{C}$ sekitar 6-7 menit yang suhu awalnya $33^{\circ} \mathrm{C}$. berdasarkan rata-rata kenaikan suhu diatas yakni $2,5^{\circ} \mathrm{C}$ per menit tanpa pengaruh dari fan dan relay yang di putus hubungkan. Dan dapat dikatakan bahwasanya elemen pemanas bekerja lebih stabil saat pengontrolan pemanas pada area setpoint yang telah ditentukan. Pengontrolan elemen pemanas nantinya dibantu oleh relay dan fan agar suhu tetap berada dibawah ambang batas suhu pengeringan optimal dan tetap menjaga dalam rentang setpoint yang berguna untuk menjaga kualitas cengkeh agar tetap baik atau tidak hangus. Relay yang berguna sebagai pemutus dan penghubung arus serta fan yang akan membuang suhu panas di dalam box pengering.

\section{E. Pengujian dan Analisa Alat Pengering Cengkeh Keseluruhan}

Pengujian alat secara keseluruhan dilakukan pada cengkeh dengan berat awal 150 gram. Pengujian dapat dimulai dengan rangkaian keseluruhan yang telah terpasang dan sesuai dengan program yang telah dibuat. Dengan menekan tombol push button akan memulai proses kerja alat. Hasil pengujian dapat dilihat pada tabel 5 .

Tabel 5. Data Hasil Pengujian dengan Alat Pengering Cengkeh

\begin{tabular}{llll}
\hline No & $\begin{array}{c}\text { Waktu } \\
\text { (jam })\end{array}$ & $\begin{array}{c}\text { Berat } \\
(\text { gram })\end{array}$ & Hasil \\
\hline
\end{tabular}

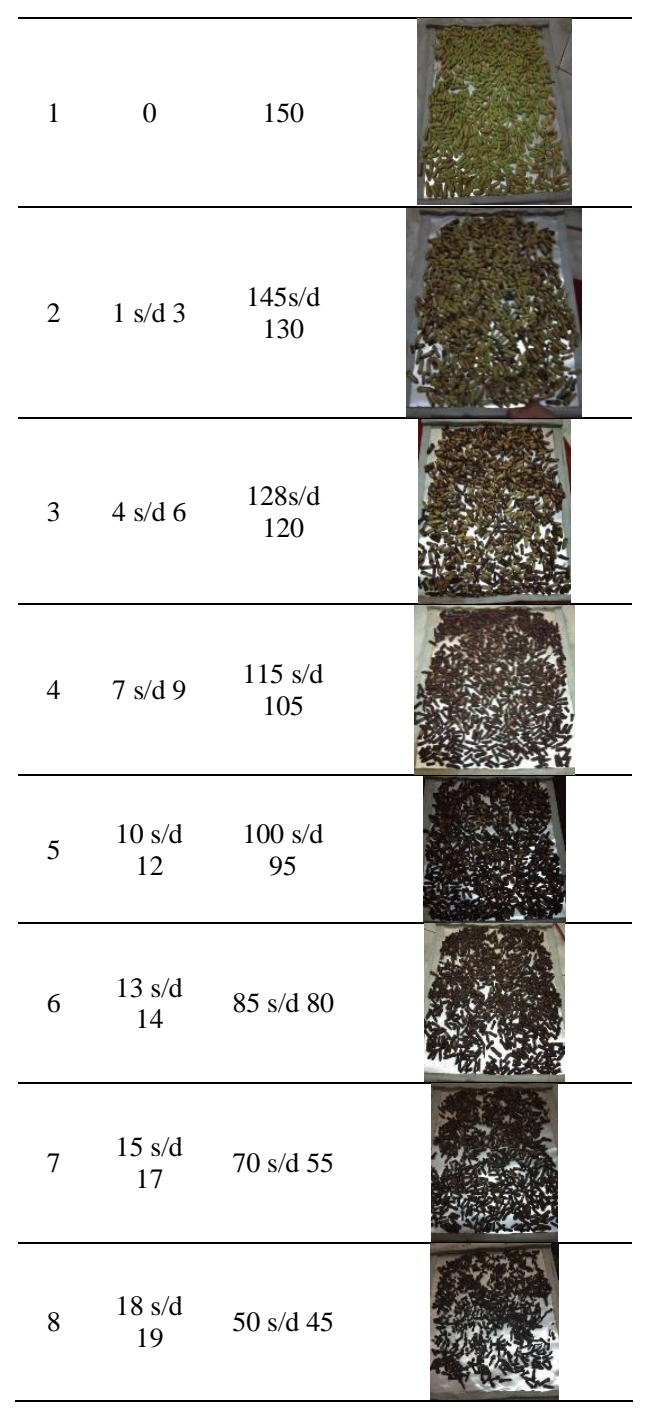

Tabel 6. Data Hasil Pengujian Cengkeh dengan Sinar Matahari

\begin{tabular}{llll}
\hline No & $\begin{array}{c}\text { Waktu } \\
\text { (jam) }\end{array}$ & $\begin{array}{c}\text { Berat } \\
\text { (gram) }\end{array}$ & Hasil \\
\hline 1 & 0 & 1300 & \\
\hline & 7 & 920 & \\
\hline & & & \\
\hline
\end{tabular}

Pengujian dilakukan dengan dua cara yaitu pengeringan yang dilakukan menggunakan alat pengering cengkeh (lihat pada tabel 5) dan pengeringan yang dilakukan menggunakan cahaya matahari langsung. Berdasarkan pengujian dan 
pengukuran bahwa pada pengeringan menggunakan alat pengering cengkeh dengan berat 150 gram cengkeh dengan kondisi basah (bewarna hijau muda) hingga menjadi kering (siap olah) terjadi selama lebih kurang 19 jam. Percobaan awal dilakukan dengan melakukan penimbangan terhadap perubahan berat dan pengecekan keadaan cengkeh pada setiap jam nya. Hingga jam yang ke 19 dapat dikatakan cengkeh sudah kering dan dapat untuk dilakukan proses pengolahan nantinya. Pengeringan selanjutnya dilakukan menggunakan cahaya matahari langsung dengan berat awal sekitar 1300 gram. Pengeringan dilakukan selama 4 hari berturut-turut dimulai dari pukul 09.00-16.00 yang berarti total waktu dari pengeringan yaitu sekitar 28 jam. Adapun suhu pengeringan dengan sinar matahari langsung yaitu antara $29^{\circ} \mathrm{C}-32^{\circ} \mathrm{C}$. Dengan perbandingan tersebut dapat disimpulkan bahwa pengeringan dengan menggunakan alat tentunya dapat menghemat waktu jika dibandingkan dengan pengeringan dengan matahari dan juga dengan alat yang telah diobservasi dapat ditentukan pengeringan dapat dikatakan sudah selesai dengan waktu yang telah ditentukan. Sedangkan dengan pengeringan menggunakan cahaya matahari langsung pengeringan dilakukan secara berangsur-angsur dan dengan waktu yang lama dengan waktu yang dikira-kira. Cengkeh dapat dikatakan kering atau siap olah apabila telah memenuhi syarat yakni kadar air yang berkurang menjadi $14 \%$, perbandingan berat awal dengan berat setelah kering 1:3, aroma kuat, warna coklat kehitaman serta mudah saat dipatahkan. Hal tersebut penulis dapatkan berdasarkan data dari jurnall dan juga tempat pengolahan lanjut dari cengkeh.

\section{KESIMPULAN}

Setelah dilakukan pengambilan data dan percobaan alat secara langsung, maka dapat ditarik kesimpulan sebagai berikut :

1. Elemen pemanas/heater pada bagian atas dengan daya 25 Watt dapat menghasilkan panas lebih cepat dan cenderung stabil dibandingkan dengan heater bagian bawah dengan daya 10 Watt
2. Dengan setpoint yang diberikan sebesar $48^{\circ} \mathrm{C}$ pengeringan cengkeh dapat berlangsung selama 19 jam.

3. Pengeringan cengkeh dengan sinar matahari memiliki kualitas yang lebih baik dengan warna yang tampak lebih kecoklatan dari pada pengeringan lewat alat.

\section{REFERENSI}

[1] Tati herlina Situmeang. 2008. "Analisis Produksi, Konsumsi, dan Harga Cengkeh Indonesia". Bogor. Program Studi Ekonomi Pertanian dan Sumber daya, Fakultas Pertanian, Institut Pertanian Bogor

[2] Dzikrullah Akbar, Purwanto, Rahmadwati. 2015. Sistem Pengendalian Suhu Pada Alat Pengering Cengkeh Menggunakan Kontroler PID. Jurnal mahasiswa TEUB Vol 3, No 4 (2015).

[3] Ebiet van Heriyanto, Harianto Harianto, Pauladie Susanto. 2014. Rancang Bangun Alat Pengering Gabah Dengan Pengendali Suhu Dan Kelembaban Ruang Berbasis Arduino Uno R3. Journal of Control and Network Systems Vol 3, No 1 (2014). Hal 120-125.

[4] Muhammad Mahrush febrianto, Fikar M.Akbar, J.Bintoro. 2017. Prototype Alat Pengering Pakaian Berbasis Arduino Uno. Jurnal Autocracy, Vol 4, No 1 Juni, 2017, 1-9.

[5] Anak Agung Gde Ekayana. 2016. Rancang Bangun Alat Pengering Rumput Laut Berbasis Mikrokontroler Arduino Uno. JPTK, UNDIKSHA, Vol. 13, No. 1, Januari 2016 : 1 - 12

[6] Yanping Wang ; Zongtao Chi. 2016.System of Wireless Temperature and Humidity Monitoring Based on Arduino Uno Platform. 2016 Sixth International Conference on Instrumentation \& Measurement, Computer, Communication and Control (IMCCC). China.

[7] He Jianfeng ; Qu Jinhui ; Wang Yuan ; Pan Hengya. 2014. The designing and porting of temperature \&humidity sensor node driver based on ARM-Linux. 2014 IEEE Workshop on Electronics, Computer and Applications. Canada

[8] DFRobot Electronic Product Wiki and Tutorial "Modul DFPlayer".https://www.dfrobot.com/wiki/index.php/DFPlayer_ Mini_SKU:DFR0299/ diakses pada tanggal 10 Juli 2018

[9] Malvino, Albert P. 1985. Prinsip-prinsip Elektronika Jilid 1. Jakarta :Erlangga 